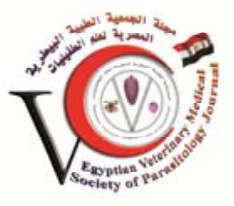

Original Article

\title{
Effect of Syzygium aromaticum and Rosmarinus officinalis extracts on Giardia lamblia and Streptococcus agalactiae isolated from Nile tilapia (Oreochromis niloticus)
}

\begin{abstract}
Nageh F Abo Dahab, Ashraf K Abd Elghany ${ }^{2}$, Hala M El Badre ${ }^{3}$

${ }^{1}$ Microbiology Department, Faculty of Science, Al-Azhar University (Assiut),

${ }^{2}$ Medical Microbiology

Department, the Institute of Oncology. Sohag

${ }^{3}$ Biochemistry Department, Faculty of Medicine, Assuit University, Egypt
\end{abstract}

\begin{abstract}
:
Two herbs (Syzygium aromaticum and Rosmarinus officinalis) were assessed for their antimicrobial activity against Giardia lamblia causing giardiasis in humans and Streptococcus agalactiae, a major fish pathogen causing streptococcosis. Each herb was extracted with 3 solvents: water, 95\% ethanol, and methanol. Methanol extract from R. officinalis was strongly active against $G$. lamblia $\left(\mathrm{IC}_{50}=0.689 \mathrm{mg} / \mathrm{mL}\right.$ ) and Syzygium aromaticum was good activity against G. lamblia $\left(\mathrm{IC}_{50}=0.755 \mathrm{mg} / \mathrm{mL}\right)$. On the other hand, ethanol extract from Syyygium aromaticum was strongly active against G. lamblia $\left(\mathrm{IC}_{50}=1.227 \mathrm{mg} / \mathrm{mL}\right.$ ) and $\mathrm{R}$. officinalis was good active against $G$. lamblia $\left(\mathrm{IC}_{50}=2.874 \mathrm{mg} / \mathrm{mL}\right)$. None of the aqueous extracts of the two plants were active against tested protozoan. Using swab paper disc assays, methanol extracts of Syzygium aromaticum and Rosmarinus officinalis produced the largest $(22.2 \pm 1.2 \mathrm{~mm})$ and $(25.4 \pm 0.9 \mathrm{~mm})$ inhibition zones, respectively. Determination of minimal inhibitory concentration (MIC) of herb extracts against $S$. agalactiae showed that the methanol extract of Rosmarinus officinalis had the lowest MIC value $(6.25 \mathrm{mg} / \mathrm{L})$. methanol extract of Sysygium aromaticum was a moderate MIC $(12.5 \mathrm{mg} / \mathrm{L})$. Such results indicate $S$. aromaticum methanol extract and ethanol extract from $R$. officinalis as possible candidates for further investigations to isolate and characterize their active principles as possible new natural anti-bacterial and anti-protozoal agents.
\end{abstract}

Key words: Syyggium aromaticum, Rosmarinus officinalis, Giardia lamblia, Streptococcus agalactiae

\section{INTRODUCTION}

Giardia lamblia is a binucleate flagellated protozoan parasite that infects the upper intestinal tract of human and many animals' species (Davies and Hibler, 1979). Giardia is an intestinal flagellate that infects a wide range of vertebrate hosts. The genus currently comprises six species, namely: G. agilis, G. ardeae, G. duodenalis, G. microti, G. muris, and G. psittaci, which are distinguished on the basis of the morphology and ultrastructure of their trophozoites (Adam, 2001). It was also a frequently encountered parasite of domestic animals, especially livestock, dogs and cats, and numerous species of wild mammals and birds, and even fish have been documented as hosts of Giardia (Hugo and Staffan, 2011). Symptoms in mammals characterized by acute watery diarrhea, dehydration and weight loss and abdominal discomfort (Adam, 2001). The infection spreads via the fecal oral route. It is generally caused by contaminated drinking water and only 10 cysts are enough to cause infection (Hugo and Staffan, 2011). Recent study revealed a low prevalence of Giardia, 3.8\% (27/709), in fish hosts. The zoonotic Giardia species, Giardia duodenalis assemblages A, B as well as $G$. duodenalis assemblage E and Giardia microti were detected. The identification of zoonotic species of Giardia highlights the public health importance of investigating parasites within fish host species (Rongchang et al., 2010). Another study investigated the occurrence of zoonotic $G$. duodenalis assemblages in fish (Tilapia nilotica and Mugil cephalus) collected from (fish farms and Nile River) at different governorates in Egypt to explore the possible role of fish in the epidemiology of human giardiasis and that contributes in the contamination of water with this pathogen (Ghoneim et al., 2012).

The most common strategy to fight aquaculture disease is the use of antibiotics; however, such usage has been reported to have adverse effects. Streptococcus agalactiae is a Gram-positive, non-spore-forming, non-acid fast, nonmotile, oxidase-negative, catalase-negative coccus with a diameter around $2 \mu \mathrm{m}$. It usually occurs in pairs or short chains. This bacterium is often referred to as Group B Streptococcus because it has group B Lancefield antigen present (Johri et al., 2006). This bacterium causes diseases in mammals, especially in human and cattle, and is a leading cause of streptococcosis in several fish species 
(Johri et al., 2006). Streptococcosis is considered a destructive disease as it can result in massive kills of fish and is responsible for heavy economic losses in many species of freshwater, marine, and estuarine fish worldwide.

The first outbreak of streptococcosis was recorded in rainbow trout (Oncorhynchus mykiss) cultured in Japan. It was later reported in the US in freshwater fish, the golden shiner (Notemigonus crysoleucas), and in seawater fish, including striped mullet (Mugil cephalus), menhaden (Brevoortia patronus), sea catfish (Arius felis). Other outbreaks of streptococcosis were reported in rainbow trout cultured in South Africa and Spain (Abutbul et al., 2004). Drug resistance in fish pathogens can occur and transfer to environmental and human pathogenic bacteria (Smith et al., 1994; Abutbul et al., 2004). Thus, accumulation of antibiotics in fish can be harmful to the environment as well as consumers (Smith et al., 1994). Such adverse effects of antibiotics lead to problems in aquaculture; therefore, only few have been approved. Many countries refuse to import cultured products in which antibiotics were used. Therefore, these problems have prompted scientists to search for an alternative to replace antibiotics in controlling diseases in aquaculture.

Herbs are an interesting alternative because they are cheaper than antibiotics. In addition, since herbs may be readily available in local markets or easily grown, user autonomy can increase. Moreover, herbs are often considered environmentally friendly, and therefore, can be used in aquaculture. Research on using herbs to control diseases in aquatic animals is increasing with the demand for environmentally friendly aquaculture processes. Many herbs have promising characteristics for use in controlling fish diseases (Rajandra, 1990). For example, Shangliang et al., (1990) reported the antimicrobial activity of 5 herb extracts, Stella aquatica, Impatiens biflora, Oenothera biennis, Artemisia vulgaris, and Lonicera japonica against bacterial and viral infections in fish; Adithepchaikarn et al., (2008) reported that Psidium guajava could control fish disease caused by Aeromonas hydrophila; and Abutbul et al. (2004) used Rosmarinus officinalis to treat Streptococcus infection in tilapia (Oreochromis sp.).

In this study, two herbs, Syzygium aromaticum and Rosmarinus officinalis were investigated for their antibacterial activity against $S$. agalactiae and antiprotozoal activity against $\mathrm{G}$. lamblia.

\section{MATERIALS AND MethodS}

\section{Standardization of protozoal suspensions}

Giardia lamblia isolated from infected tilapia (O. niloticus), and obtained from Parasitology Department, Faculty of medicine, University at Assiut. G. lamblia trophozoites were grown axenically in Diamond's modified culture medium TYI-S-33 broth medium was used for stock culture of $G$. lamblia; when the logarithmic phase of growth was reached, the trophozoites were detached from the substrate by cooling on water-ice for $20 \mathrm{~min}$. They were then distributed into $1.5 \mathrm{~mL}$ volumes of fresh culture medium in polypropylene microcentrifuge tubes to achieve inocula ranging from $1.0 \times 10^{3}$ to $5.0 \times 10^{5}$ per $\mathrm{mL}$ as determined by counting in a Neubauer hemocytometer. After incubation for $48 \mathrm{~h}$ at $37^{\circ} \mathrm{C}$, the number of trophozoites was again counted (Diamond et al., 1978).

\section{Bacteria and culture conditions}

The $S$. agalactiae used in this study was $S$. agalactiae isolated from infected tilapia (O. niloticus), and obtained from Department of Fish Disease, Research Institute for Animal Health, Egypt. The identity of each bacterial strain was confirmed using the API 20 Strep test kit (bioMérieux Industry, Hazelwood, MO, USA). The bacterial culture was grown in brain heart infusion (BHI) medium at $25^{\circ} \mathrm{C}$, and a stock of the organism was stored at $-80^{\circ} \mathrm{C}$ in $\mathrm{BHI}$ broth supplemented with 15\% glycerol (Gorman and Adley, 2004). .

\section{Plant materials and preparation of herb extracts}

The herbs used were: Syzgium aromaticum (clove), Rosmarinus officinalis (rosemary). Herbs were purchased from herb shops in Cairo, Egypt. Three different solvents, distilled water, 95\% ethanol, and $99.8 \%$ methanol, were used to prepare extracts from each herb. In each case, the herb was oven-dried at $80^{\circ} \mathrm{C}$ for $72 \mathrm{~h}$, finely ground in a mortar, and extracted with solvent in a ratio of $1: 10(\mathrm{w} / \mathrm{v})$ for $24 \mathrm{~h}$ at room temperature. The mixture was then centrifuged at 13,000 rpm for $10 \mathrm{~min}$ at room temperature and the supernatant collected for filtration. For aqueous extracts, the filtrates were frozen at $-80^{\circ} \mathrm{C}$ for $48 \mathrm{~h}$ before being freeze-dried. For the other extracts, the filtrates were evaporated to dryness in a rotary evaporator before being frozen at $-80{ }^{\circ} \mathrm{C}$ for $48 \mathrm{~h}$ prior to being freeze-dried. Two extracts were stored at $-20{ }^{\circ} \mathrm{C}$ in glass vials until use. For antimicrobial activity testing and determination of minimal inhibitory concentration (MIC), the concentration of each herb extract was adjusted to $100 \mathrm{mg} / \mathrm{mL}$ (Bauer et al., 1966). 


\section{Column Chromatography and Gas Chromatography-Mass Spectrum Analysis (GC-MS)}

One gram of the crude methanol extract was subjected to column chromatography using silica gel (100-200 mesh) and eluted with ethyl acetate. This ethyl acetate fraction of the plant extracts was taken for GC-MS analysis, since ethyl acetate could extract most of the bioactive compounds (Sangeetha and Vijayalakshmi, 2011).

\section{Antiprotozoal activity}

Susceptibility of $G$. lamblia to the antimicrobial agents was determined by the culture method of Hill et al. (1986) with some modifications: serial dilutions of drugs were prepared in $1.5 \mathrm{~mL}$ volumes of culture medium in microcentrifuge tubes. The tubes were then inoculated with $G$. lamblia to achieve an inoculum of $5 \times 10^{4}$ trophozoites $/ \mathrm{mL}$. Controls, prepared by adding drug-free solvents to the culture media, were similarly inoculated. Each test included metronidazole as positive control, a negative control (culture medium plus trophozoites and DMSO), and a blank (culture medium). The metronidazole compound was dissolved in DMSO $67 \mu \mathrm{g} / \mathrm{mL}$. After incubation for $48 \mathrm{~h}$ at $37^{\circ} \mathrm{C}$, trophozoites were detached by chilling on iced water for $20 \mathrm{~min}$ and $50 \mu \mathrm{l}$ of each culture tube was subcultured into $1.5 \mathrm{~mL}$ of fresh culture medium without drug. After incubation for a further $48 \mathrm{~h}$, the final number of parasites was determined by counting in a Neubauer hemocytometer. The number of viable trophozoites remaining after exposure to drug for $48 \mathrm{~h}$ was deduced from the number of trophozoites attained in drug-free control cultures. The $50 \%$ inhibitory concentration $\left(\mathrm{IC}_{50}\right)$ was defined as the concentration of the drug that inhibited growth by $50 \%$. The results of antiprotozoal activity of the different extracts used were calculated as the percentage of growth inhibition when compared with the controls grown without plant extracts, the best straight line was determined by regression analysis, and the concentration that caused $50 \%$ inhibition $\left(\mathrm{IC}_{50}\right)$ were calculated for the log of the concentration using Graph Pad Prism (Katiyar et al., 1994). Each experiment was done in triplicate.

The mortality \% of parasite for each extracts activity was carried out according to the following formula:

\section{Mortalty of parasite $(\%)=$$$
\frac{\text { Control Negative-Tested Sample }}{\text { Control Wegative }} \times 100
$$

\section{Antibacterial activity testing}

Antibacterial activities of the herb extracts against $S$. agalactiae were examined using a swab paper disc method with some modifications. $40 \mu \mathrm{l}$ of each herb extract were spotted on a sterile paper disc, placed onto a $\mathrm{BHI}$ agar plate, spread with a swab of overnight culture containing colony forming units (cfu) of $S$. agalactiae (approximately $10^{8} / \mathrm{cfuL}$ ). Each extract was tested in triplicate. Negative control were prepared in the same way except that $40 \mu \mathrm{l}$ of suitable solvent dimethylsulphoxide (DMSO) were used instead of the herb extracts. Oxytetracycline (5 $\mathrm{\mu g}$ on sterile paper disc), a common antibiotic used, served as the positive control. The prepared agar plates were then incubated at $25^{\circ} \mathrm{C}$ for $18 \mathrm{~h}$, and their growth inhibition zones were same as the total diameter of the growth-free zones around the discs. The diameter of the growth inhibition zone in the negative control treatment was subtracted (in case of no growth inhibition in the negative control treatment, only the diameter of the disc was subtracted) giving the zones of growth inhibition beyond the paper disc (Bauer et al., 1966).

\section{Determination of MIC}

To determine the MIC of the herb extracts against $S$. agalactiae, Serial concentrations of two plant extracts were prepared from this crude extract to contain, 0.049, $0.098,0.195,0.391,0.781,1.562,3.125,6.25,12.5,25$ and $50 \mathrm{mg} / \mathrm{mL}$. The series of concentrations were used to detect the minimum inhibitory concentration (MIC) of two plant extracts by disc diffusion method (Bauer et al., 1966). The series of concentrations were kept in refrigerator at $4^{\circ} \mathrm{C}$ until used. MIC was defined as the lowest concentration of extracts that inhibited visible growth. The herb extracts with the MIC values of $50 \mathrm{mg}$ $\mathrm{mL}^{-1}$ or more, $25 \mathrm{mg} \mathrm{mL}^{-1}$ and $12.5 \mathrm{mg} / \mathrm{mL}$ or less were declared to have weak, moderate and strong antimicrobial activities, respectively.

\section{Phytochemical analysis}

Preliminary screening of phytochemical content of different extracts was carried out in order to discover the antimicrobial activities against $G$. lamblia that were used in this study. Tannins, alkaloids, saponins, steroids, terpeniods, flavonoids, volatile oils and cardiac glycosides were determined by standard technique. GC-MS analysis was carried out on a HP 5972 Mass Selective Detector and Agilent 6890 Series Autosampler (Agilent Technologies, Santa Clara, CA, USA) and gas chromatograph interfaced 
to a mass spectrometer (GC-MS) (Sangeetha and Vijayalakshmi, 2011).

\section{Identification of components}

The spectrum of the unknown component was compared with the spectrum of the known components stored in the NIST library by using the time retention (TR). The Name, Molecular weight and Structure of the components of the test materials were ascertained.

\section{Statistical analysis}

Each parameter was tested in triplicate. The values were expressed as mean \pm standard deviation (SD). Also determination of $p$-value (two tailed) of the results by using Graph Pad Prism (Katiyar et al., 1994).

\section{RESULTS}

Antiprotozoal activity of Syzgium aromaticum crude extracts

The $50 \%$ growth inhibition $\left(\mathrm{IC}_{50}\right)$ of methanol, ethanol, and aqueous extracts from $S$. aromaticum at different concentrations $(0.098-50 \mathrm{mg} / \mathrm{mL})$ against G. lamblia trophozoites cultures was displayed in (Table 1 and Figure 1). The aqueous showed no activity against trophozoites of $G$. lamblia. The methanol extract $S$. aromaticum showed strong activity against trophozoites of G. lamblia followed by ethanol extract with an $\mathrm{IC}_{50}$ of 0.755 and 1.227 with the highest trophozoite mortality rate obtained $(95.3 \pm 0.2 \%)$ and $(92.3 \pm 0.1 \%)$ respectively. Trophozoites of $G$. lamblia were affected with increasing concentrations of methanol extracts and ethanol of the plant S. aromaticum. Metronidazol (MET) at $67 \mu \mathrm{g} / \mathrm{mL}$ concentration were inhibited all growth culture of $100 \%$ trophozoites. The decline in the percentage of trophozoites number was significant for all concentration tested $(p<0.05)$.

\section{Antiprotozoal activity of Rosmarinus officinalis crude extracts}

The $50 \%$ growth inhibition $\left(\mathrm{IC}_{50}\right)$ of pet. ether, ethyl acetate, methanol and aqueous extracts from $R$. officinalis at different concentrations (0.098 - $50 \mathrm{mg} \mathrm{mL}^{-1}$ ) against $G$. lamblia trophozoites cultures was displayed in (Table 2 and Figure 2). The aqueous extract showed no activity

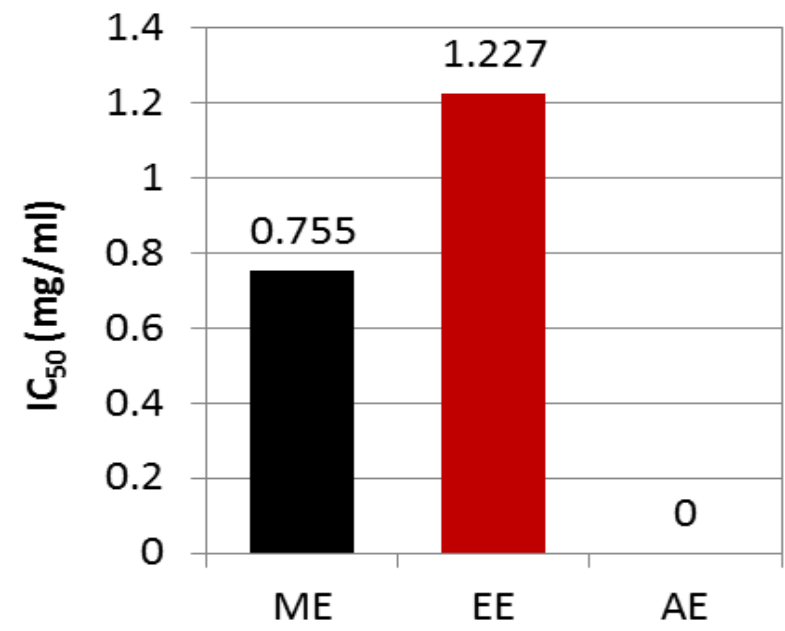

Figure 1: Inhibitory concentration $50 \%$ (IC50) of S. aromaticum crude extracts against tested G. lamblia

Table 1: G. lamblia trophozoites mortality rate and $\mathrm{IC}_{50}$ after $48 \mathrm{~h}$ exposure to $\mathrm{S}$. aromaticum extracts

\begin{tabular}{|c|c|c|c|c|c|c|}
\hline \multirow{2}{*}{$\begin{array}{l}\text { Concentration of plant extract } \\
\mathrm{mg} / \mathrm{mL}\end{array}$} & \multicolumn{2}{|c|}{ ME } & \multicolumn{2}{|c|}{ EE } & \multicolumn{2}{|c|}{$\mathrm{AE}$} \\
\hline & TM\% & $I C_{50}$ & TM\% & $I C_{50}$ & TM\% & $I C_{50}$ \\
\hline 50 & $95.3 \pm 0.2$ & \multirow{12}{*}{$0.755^{*}$} & $92.3 \pm 0.1$ & \multirow{12}{*}{$1.227^{*}$} & 0 & \multirow{12}{*}{$\cdot$} \\
\hline 25 & $89.3 \pm 0.1$ & & $86.3 \pm 0.1$ & & • & \\
\hline 12.5 & $81.3 \pm 0.1$ & & $80.3 \pm 0.1$ & & - & \\
\hline 6.25 & $73.7 \pm 0.6$ & & $74.7 \pm 0.6$ & & • & \\
\hline 3.125 & $70.7 \pm 0.8$ & & $68.7 \pm 0.8$ & & • & \\
\hline 1.562 & $64.7 \pm 0.5$ & & $64.7 \pm 0.5$ & & - & \\
\hline 0.781 & $53.7 \pm 0.6$ & & $52.7 \pm 0.6$ & & - & \\
\hline 0.391 & $44.3 \pm 0.2$ & & $42.3 \pm 0.2$ & & - & \\
\hline 0.195 & $23.7 \pm 0.5$ & & $23.7 \pm 0.5$ & & - & \\
\hline 0.098 & $13.3 \pm 0.1$ & & $13.3 \pm 0.1$ & & • & \\
\hline DMSO (-ve C) & 0 & & 0 & & - & \\
\hline Metronidazole (+ve C) & $100 \pm 0.0$ & & $100 \pm 0.0$ & & $\cdot$ & \\
\hline
\end{tabular}

Values are means of inhibition effect $(\%) \pm S D(n=3) *$ Correlation is significant at the $p<0.05$ level (2-tailed).

$\mathrm{TM} \%=$ Trophozoite mortality, $-\mathrm{ve} \mathrm{C}=$ negative contole $+\mathrm{ve} \mathrm{C}=$ positive control

$\mathrm{ME}=$ Methanol extract, $\mathrm{EE}=$ Ethanol extract, $\mathrm{AE}=$ Aqueous extract,

$I_{50}=$ Inhibitory concentration of $50 \%, 0$ : no sensitivity 
Table 2: G. lamblia trophozoites mortality rate and $I_{50}$ after $48 \mathrm{~h}$ exposure to $R$. officinalis extracts

\begin{tabular}{|c|c|c|c|c|c|c|}
\hline \multirow{2}{*}{$\begin{array}{l}\text { Concentration of plant extract } \\
\mathrm{mg} / \mathrm{mL}\end{array}$} & \multicolumn{2}{|c|}{ ME } & \multicolumn{2}{|c|}{ EE } & \multicolumn{2}{|c|}{$\mathrm{AE}$} \\
\hline & TM\% & $I C_{50}$ & TM\% & $I C_{50}$ & TM\% & $I C_{50}$ \\
\hline 50 & $96.7 \pm 0.8$ & & $92.0 \pm 0.6$ & & 0 & \\
\hline 25 & $90.0 \pm 0.5$ & & $86.0 \pm 0.5$ & & - & \\
\hline 12.5 & $84.0 \pm 0.7$ & & $80.0 \pm 0.5$ & & - & \\
\hline 6.25 & $78.0 \pm 0.3$ & & $74.0 \pm 0.5$ & & · & \\
\hline 3.125 & $72.0 \pm 0.5$ & & $68.0 \pm 0.4$ & & - & \\
\hline 1.562 & $62.3 \pm 0.1$ & 0 600* & $58.3 \pm 0.1$ & 2 974* & - & - \\
\hline 0.781 & $52.0 \pm 0.3$ & $0.689^{*}$ & $47.3 \pm 0.2$ & $2.874^{*}$ & - & - \\
\hline 0.391 & $41.0 \pm 0.3$ & & $36.0 \pm 0.6$ & & · & \\
\hline 0.195 & $31.0 \pm 0.5$ & & $26.0 \pm 0.3$ & & - & \\
\hline 0.098 & $19.0 \pm 0.3$ & & $16.0 \pm 0.5$ & & - & \\
\hline DMSO (-ve C) & 0 & & 0 & & - & \\
\hline Metronidazole (+ve C) & $100 \pm 0.0$ & & $100 \pm 0.0$ & & - & \\
\hline
\end{tabular}

Values are means of inhibition effect $(\%) \pm$ S.D $(n=3) *$ Correlation is significant at the $p<0.05$ level (2-tailed).

$\mathrm{TM} \%=$ Trophozoite mortality, $-\mathrm{ve} \mathrm{C}=$ negative control $+\mathrm{veC}=$ positive control

$\mathrm{ME}=$ Methanol extract, $\mathrm{EE}=$ Ethanol extract, $\mathrm{AE}=$ Aqueous extract,

$I C_{50}=$ Inhibitory concentration of $50 \%, 0$ : no sensitivity

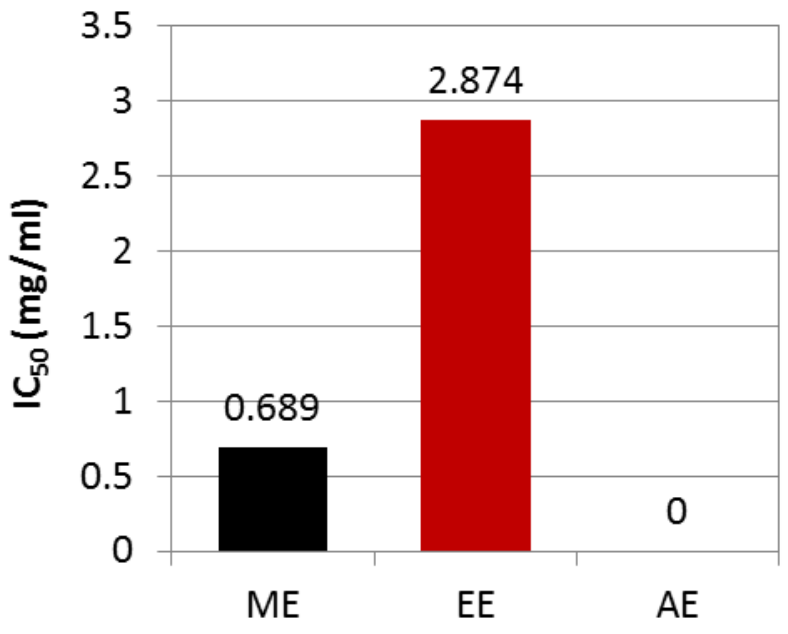

Figure 2: Inhibitory concentration $50 \%$ (IC50) of R. offisinalis crude extracts against tested $\mathrm{G}$. lamblia

activity against trophozoites of $G$. lamblia. The methanol extract $R$. officinalis showed strong activity against trophozoites of $G$. lamblia followed by ethanol extract with an $\mathrm{IC}_{50}$ of 0.689 and $2.874 \mathrm{mg} / \mathrm{mL}$ with the highest trophozoite mortality rate obtained $(96.7 \pm 0.8 \%)$ and $(92.0 \pm 0.6 \%)$ respectively. Trophozoites of $G$. lamblia were affected with increasing concentrations of methanol and ethanol extracts of the plant $R$. officinalis. Metronidazole (MET) at $67 \mu \mathrm{g} / \mathrm{mL}$ concentration were inhibited all growth culture of $100 \%$ trophozoites. The decline in the percentage of trophozoites number was significant for all concentration tested $(p<0.05)$.
Table 3: Antibacterial activity of herbs extracted in different solvents as determined by swab paper disc assay against $S$. agalactiae

\begin{tabular}{lccc}
\hline Herbs & \multicolumn{3}{c}{ Inhibition zone size $(\mathrm{mm})$} \\
\cline { 2 - 4 } \multicolumn{1}{c}{ Solvent } & methanol & ethanol & water \\
\hline S. aromaticum & $22.2 \pm 1.2$ & $20.8 \pm 1.2$ & $10.3 \pm 0.6$ \\
$\begin{array}{l}\text { R. officinalis } \\
\text { DMSO }\end{array}$ & $25.4 \pm 0.9$ & $20.2 \pm 0.4$ & $18.1 \pm 1.0$ \\
$\begin{array}{l}\text { (-ve control) } \\
\begin{array}{l}\text { Oxytetracycline } \\
\text { (+ve control) }\end{array}\end{array}$ & $(-)$ & \\
\hline
\end{tabular}

Values are means of Inhibition zone size $(\mathrm{mm}) \pm \mathrm{SD}(\mathrm{n}=3)$.

*Correlation is significant at the $p<0.05$ level (2-tailed), (-): No sensitivity.

\section{Antibacterial activity testing}

The swab paper disc assay results are presented in Table 3. Two herb extracts had antimicrobial activity against $S$. agalactiae; however, different degrees of inhibition were observed. Of the herb extract types used in this study, the 98.8\% methanol extracts exhibited the strongest antimicrobial activity, followed by $95 \%$ ethanol and aqueous extracts. Based on inhibition zone sizes, methanol extract of $R$. officinalis produced the largest inhibition zone, whereas aqueous extract of $S$. aromaticum produced the smallest. 


\section{Determination of MIC}

The MIC values of herb extracts are shown in Table 4 . In general, there was a significant correlation between the findings for the swab paper disc method and the MIC determination assay. Based on MIC values, Clove and Rosemary extracts were declared to have strong (MIC values $6.5 \mathrm{mg} / \mathrm{mL}$ ), moderate (MIC values of $12.5 \mathrm{mg} / \mathrm{mL}$ ), and weak (MIC values $50 \mathrm{mg} / \mathrm{mL}$ ) inhibitory activity with methanol, ethanol and water extracts, respectively of clove and rosemary. None of the $95 \%$ ethanol extracts exhibited moderate activity. Among the herb extracts, showing strong antimicrobial activity, the methanol extract of $R$. officinalis had the lowest MIC $(6.5 \mathrm{mg} / \mathrm{mL})$. Within the group of extracts with weak activity, only one extract (aqueous extracts of $S$. aromaticum) had an MIC value of $>50 \mathrm{mg} / \mathrm{mL}$.

\section{Phytochemical analysis}

Some secondary products of $S$. aromaticum and Rosmarinus officinalis extracts contained flavonoid, volatile oil, sterols \& triterpins, saponins, tannins and cardiac glycosides. GC-MS analysis for volatile compounds methanol extract of $S$. aromaticum contained sixteen compounds were identified. The major component was phenol, 2-methoxy-3-(2-propenyl)-[eugenol] (71.04\%), phenol, 2-methoxy-4-(2-propenyl)-, acetate (12.03\%) and caryophyllene (8.41\%). Also, GC-MS analysis for volatile compounds methanol extract of Rosmarinus officinalis contained twenty six volatile compounds were identified. The major component were $\alpha$-pinene (19.32\%), camphor (6.12\%), 1.8-cineole (5.44\%), camphene (6.03\%), $\beta$-pinene (5.60\%), bornylacetate (4.55\%), limonene (3.66\%), borneol (3.20\%), terpinen-4-ol (1.99\%) and carvone (1.14\%).

\section{Discussion}

Although antibiotics have been used to control bacterial infections in fish for many years, several antibiotics have been banned from use in aquaculture due to their adverse effects. In addition, products from aquaculture facilities using antibiotics are not accepted by many countries. Therefore, finding an alternative antimicrobial substance to replace antibiotics has become an issue of interest of many research groups. In this study, two herbs Syzgium aromaticum (clove) and Rosmarinus officinalis (rosemary) were evaluated for their antiprtozoal activity against $G$. lamblia and antibacterial activity against $S$. agalactiae. The essential oil inhibited trophozoites adherence since the first hour of incubation and was able to kill almost $50 \%$ of the parasites population in a time dependent manner.
Table 4: Minimal inhibitory concentrations (MIC) of herbs extracted in different solvents against $S$. agalactiae

\begin{tabular}{lccc}
\hline Herbs & \multicolumn{3}{c}{ MIC (mg/L) } \\
\cline { 2 - 4 } \multicolumn{1}{c}{ Solvent } & methanol & ethanol & water \\
\hline S. aromaticum & 12.5 & 25 & $(-)$ \\
R. officinalis & 6.25 & 12.5 & 50 \\
\hline
\end{tabular}

(-): No sensitivity

The eugenol inhibited G. lamblia trophozoites adherence since the third hour and not induce cell lyses (Machado et al., 2003). The main morphological alterations were modifications on the cell shape, presence of precipitates in the cytoplasm, autophagic vesicles, internalization of flagella and ventral disc, membrane blebs, and intracellular and nuclear clearing. Taken together, our findings lead us to propose that eugenol was responsible for the antigiardial activity of the $S$. aromaticum essential oil and both have potential for use as therapeutic agents against giardiasis (Machado et al., 2003). Plants and their extracts and essential oils have been used for many years in the treatment of several diseases, including parasite infections (Jones, 1996). The essential oils can be extracted from different parts of the plant, obtained by crushing or by distillation. Others performed a literature review of the essential oils that have been shown to possess activity against E. histolytica, G. lamblia, T. vaginalis, T. cruzi, and/ or Leishmania sp (Perez et al., 2012).

In this study antigiardial activity of $R$. officinalis extracts may be attributed to their phytoconstituents which contained it. Plants and their extracts and essential oils have been used for many years in the treatment of several diseases, including parasite infections (Jones, 1996). The essential oils can be extracted from different parts of the plant, obtained by crushing or by distillation. Others performed a literature review of the essential oils that have been shown to possess activity against $E$. histolytica, G. lamblia, T. vaginalis, T. cruzi, and/or Leishmania sp (Perez et al., 2012). Interestingly, many herbs used to treat diarrheal diseases contain considerable quantities of some of these flavonoids (e.g., Quercus robur, Croton lechleri, and Hamamelis virginiana) (Cai et al., 1991; Ubillas et al., 1994; Blumenthal et al., 2000). This study found that aqueous, 95\% ethanol, and methanol extracts of two herbs used in this study were able to inhibit the growth of $S$. agalactiae. This may be because the herbs have more than one extractable active compound that provides 
antimicrobial activity. Clove buds and their essential oils have been known to possess various antimicrobial and antioxidant properties (Fu et al., 2007). Shelef (1983) reported that the essential oil substance isolated from clove, inhibited bacteria in culture media and also discovered that most of the antimicrobial substances were phenol compounds such as eugenol, thymol and carvacol. Burt (2004) proposed that different modes of action are involved in the antimicrobial activity of EOs. The activity may, in part, be due to their hydrophobicity, responsible for their partition into the lipid bilayer of the cell membrane, leading to an alteration of permeability and a consequent leakage of cell contents (Burt, 2004). Recent investigations on the antimicrobial action of some EOs showed disruption of the bacterial and fungal membrane (Cox et al., 2000, 2001; Hammer et al., 2004; Di Pasqua et al., 2007; Bakkali et al., 2008). Eugenol is the main volatile compound of extracted oil from bud $S$. aromaticum that is used in traditional medicine, as a bactericide, fungicide (Arras and Usai, 2001; Ayoola et al., 2008), anesthetic, and others (Santos et al., 2009). Tannin is a compound, which has antimicrobial activity, and can be isolated from plants by water (Scalbert, 1991), ethanol (Silva et al., 1997), and methanol extraction (Taylor et al., 1997). Moreno et al. (2006) reported that rosemary plants are rich sources of phenolic compounds with high antimicrobial activity against both Gram positive and Gram negative bacteria. Antimicrobial activities of plant essential oils have been known for centuries, but their strong flavor limited their use in food (Del Campo et al., 2000). Rosemary plants are rich sources of phenolic compounds with high antioxidative and antimicrobial properties, but their antimicrobial activities have not been deeply characterized (Moreno et al., 2006). There is also some evidence that minor components have a critical part in antibacterial activity, possibly by producing a synergistic effect between other components (Burt, 2004). The absence of inhibition zone does not necessarily mean that compounds are inactive. For example, non-polar compounds may not diffuse into the culture medium (Moreno et al., 2006). The antimicrobial activity of essential oils fractions from rosemary has been reported several times (Tepe et al., 2005 ; Sacchetti et al., 2005) although this activity was scarcely investigated in other fractions. In another report an inhibitory activity of a commercial rosemary extract against $S$. aureus was described, but in this case the composition and the active compound were not given (Plouzek et al., 1999). It was reported that an antimicrobial action of phenolic compounds was related to the inactivation of cellular enzymes, which depended on the rate of penetration of the substance into the cell or caused by membrane permeability changes (Shahidi and Naczk, 2004). The mechanism of action of terpenes is not fully understood but it is in general speculated to involve membrane disruption by the lipophilic compounds (Cowan, 1999). Besides, another research done by Cervenka et al. (2006) on methanol and chloroform extracts of 17 plants such as rosemary, sage, chamomile and cinnamon, showed that methanol extract of these plants had higher antimicrobial effects than their chloroform extracts. The difference in obtained results is due to using different kinds and different concentrations of extracts in our study and previous researches. The antibacterial activity of clove is attributed to eugenol ( 2 methoxy-4 allyl-phenol) (Gupta et al., 2008). High tannin content (10-19\%) in clove also provides additional antimicrobial activity (Nanasombat and Lohasupthawee, 2005).

\section{REFERENCES}

Abutbul, S., Golan-Goldhirsh, A., Barazani, O., and Zilberg, D. (2004): Use of Rosmarinus officinalis as a treatment against Streptococcus iniae in tilapia (Oreochromis sp.), Aquaculture, 238, 97-105.

Adam R.D. (2001): Biology of Giardia lamblia, Clinical Microbiology Review, 14: 447-475.

Adithepchaikarn, P., Phumkhachorn, P., and Rattanachaikunsopon, P. (2008): Potential of Psidium guajava supplemented fish diets in controlling Aeromonas hydrophila infection in tilapia (Oreochromis niloticus). J. Biosci. Biotechnol., 106, 419-424.

Arras, G.; Usai, M. (2001): Fungitoxic activity of essential oils against four post-harvest citrus pathogens: Chemical analysis of Thymus capitates oil and its effect in subatmospheric pressure conditions. J. Food Prot. 64, 10251029.

Ayoola, G.A.; Lawore, F.M.; Adelowotan, T.; Aibinu, I.E.; Adenipekun, E.; Coker, H.A.B. and Odugbemi, T.O. (2008): Chemical analysis and antimicrobial activity of the essential oil of Syzigium aromaticum (clove). African J. Microbiol. Res. 2, 162-166.

Bakkali, F.; Averbeck, S.; Averbeck, D. and Idaomar, M. (2008): Biological effects of essential oils-A review. Food Chem. Toxicol., 46: 446-475.

Bauer, A.W.; Kirby, W.M.M.; Sherris, J.C. and Turck, M. (1966): Antibiotic susceptibility testing by a standardized single disk method, Am. J. Clin. Pathol. 45: 493- 496.

Blumenthal, M. ; Brinckmann, J. and Goldberg, A., (2000): Herbal Medicine: Expanded Commission E Monographs. Austin, TX: Integrative Medicine the American Botanical Council, Austin/Texas, 367-375. 
Burt, S.A. (2004): Essential oils: their antibacterial properties and potential applications in foods: a review. Inter .J. Food Microbiol. , 94:223-253.

Cabrita, J., and Gomes, E. (1997): Antimicrobial activity of Terminalia macroptera root, J. Ethnopharmacol., 57:2037.

Cai, Y.; Evans, F.J.; Roberts, M.F.; et al. (1991): Polyphenolic compounds from Croton lechleri. Phytochemistry, 30:2033-2040.

Cervenka, L.; Peskova, I.; Foltynova, E.; Pejchalova, M.; Brozkova, I. and Vytrasova, J. (2006): Inhibitory effects of some spice \& herbal extracts against arcobacter butzeln, Curr Microbiol., 53: 435-9.

Cowan, M.M. (1999): Plant products and antimicrobial agents. Clinical Microbiology Reviews 12, 564-582.

Cox, S.D.; Mann, C.M.; Markham, J.L.; Bell, H.C.; Gustafson, J.E.; Warmington, J.R. and Wyllie, S.G. (2000): The mode of antimicrobial action of the essential oil of Melaleuca alternifolia (tea tree oil). J. Appl. Microbiol., 88, 170-175.

Cox, S.D.; Mann, C.M.; Markham, J.L.; Gustafson, J.E.; Warmington, J.R., Wyllie, S.G. (2001): Determining the antimicrobial actions of tea tree oil. Molecules 6:87-91.

Davies R.B. and Hibler C.P. (1979): Animal reservoir and cross species transmission of Giardia, p: 104.

Del Campo, J.; Amiot, M.J. and Nguyen, C. (2000): Antimicrobial effect of rosemary extracts. J. Food Protection, 10: 1359-1368.

Di Pasqua, R.; Betts, G.; Hoskins, N.; Edwards, M.; Ercolini, D. and Mauriello, G. (2007): Membrane toxicity of antimicrobial compounds from essential oils. J. of agricultural and food chemistry 55(12): 4863-4870.

Diamond, L.S.; Harlow, D.R. and Cunnick, C.C. (1978): A new medium for the axenic cultivation of Entamoeba histolytica and other Entamoeba. Trans. R. Soc. Trop. Med. Hyg. 72:431-432.

Fu, Y., Zu, Y., Chen, L., Shi, X., Wang, Z. Sun, S. and Efferth, T. (2007): Antimicrobial activity of clove and rosemary essential oils alone and in combination. Phytother. Res. 21: 989-994.

Ghoneim, N.H. ; Abdel-Moein, K.A. ; Saeed, H. (2012): Fish as a possible reservoir for zoonotic Giardia duodenalis assemblages. PubMed ,110(6):2193-6.

Gorman, R. and Adley, C.C. (2004): An evaluation of five preservation techniques and conventional freezing temperatures of $-20^{\circ} \mathrm{C}$ and $-85^{\circ} \mathrm{C}$ for long-term preservation of Campylobacter jejuni. Letters in Applied Microbiology, 38, 306-310.

Gupta, C.; Garg, A.P.; Uniyal, R.C. and Kumari, A. (2008): Antimicrobial activity of some herbal oils against common food-borne pathogens. Afr. J. Microbiol. Res. 2:258-261.

Hammer, K.A.; Carson, C.F. and Riley, T.V. (2004): Antifungal effects of Melaleuca alternifolia (tea tree) oil and its components on Candida albicans, Candida glabrata and Saccharomyces cerevisiae. J. Antimicrob. Chemother., 53, 1081-1085.
Health Section News, 3, 3-4.

Hill, D.R.; Pohl, R. and Pearson, R.D. (1986): Giardia lamblia: a culture method for determining parasite viability. Am. J. Trop. Med. Hyg. , 35: 1129-1133.

Hugo D. Lujan; Staffan Svard (2011): Giardia a Model Organism, Springer-Verlag/Wien, Austria, p: 17.

Johri, A. K., Paoletti, L. C., Glaser, P., Dua, M., Sharma, P. M., Grandi, G., and Rappuoli, R. (2006): Group B Streptococcus: global incidence and vaccine development. Nat. Rev. Microbiol., 4, 932-942 .

Jones, F.A. (1996): Herbs-useful plants. Their role in history and today. Eur. J. Gastroenterol. Hepatol., 8: 12271231.

Katiyar, S.K.; Gordon, V.R.; McLaughlin, G.L. and Edlind, T.D. (1994): Antiprotozoal activities of benzimidazoles and correlations with betatubulin sequence. Antimicrob. Agents Chemother. 38:2086-2090.

Machado T, Pinto A, Pinto M, Leal I, Silva M, Amaral A, Kuster R, Netto dosSantos K (2003): In vitro activity of Brazilian medicinal plants, naturally occurring naphthoquinones and their analogues, against methicillinresistant Staphylococcus aureus. Int J Antimicrob Agents. 21:279-284.

Moreno, S.; Scheyer, T.; Romano, C.S. and Vojnov, A.A. (2006): Antioxidant and antimicrobial activities of rosemary extracts linked to their polyphenol composition. Free Radical Research, 40: 223-231.

Nanasombat, S., Lohasupthawee, P. (2005): Antibacterial activity of crude ethanolic extracts and essential oils of spices against Salmonella and other enterobacteria. J. Food Science and Technology 5 (3):527-538.

Pérez, S. G.; Ramos-López, M.A.; Sánchez-Miranda, E.; Fresán-Orozco, M.C. and Pérez-Ramos, J. (2012): Antiprotozoa activity of some essential oils, Journal of Medicinal Plants Research Vol. 6(15), pp. 2901-2908.

Plouzek, C.A.; Ciolino, H.P.; Clarke, R. and Yeh, G.C. (1999): Inhibition of P-glycoprotein activity and reversal of multidrug resistance in vitro rosemary extract. Eur J. Cancer; 35:1541-1545.

Rajandra, K.R. (1990): Prevention and control of fish diseases by herbal medicine, Fish

Rongchang Y.; Anna R.; Alan L.; Una R. (2010): Identification of zoonotic Giardia genotypes in fish. International Journal for Parasitology 40(7):779-785.

Sacchetti, G. et al., (2005): Comparative evaluation of 11 essential oils of different origin as functional. Food Chemistry, Ferrara/Macas/Parma, v. 91, n. 4, p. 621-632.

Sangeetha, J. and Vijayalakshmi, K. (2011): Determination of Bioactive Components of Ethyl Acetate Fraction of Punica granatum Rind Extract", Int. J. of Pharmaceutical Sciences and Drug Research, Vol. 3, No. 2, pp. 116-122.

Santos, A.L.; Chierice, G.O.; Alexander, K.S.; Riga, A. and Matthews, E. (2009): Characterization of the raw essential oil eugenol extracted from Syzygium aromaticum L. J. Therm. Anal. Calorim. 96, 821-825. 
Scalbert, A. (1991): Antimicrobial properties of tannins, Phytochemistry, 30, 3875-3883.

Shahidi, F. and Naczk, M. (2004). editors. Nutricional and pharmacological effects of food phenolics Phenolics in food and nutraceuticals. New York: CRC Press LLC; $p$ 331402.

Shangliang, T., Hetrick, F. M., Roberson, B.S., and Baya, A. (1990): The antibacterial and antiviral activity of herbal extracts for fish pathogens. J. Ocean Uni Qingdao. 20:5360.

Shelef, L.A. (1983): Antimicrobial effects of spices. J. Food safety. 6: 29-44.
Silva, O., Duarte, A., Pimental, M., Viegas, S., Barroso, H., Machado, J., et al. (1994): Bacterial resistance to antimicrobial agent used in fish farming: a critical evaluation of method and meaning, Ann. Rev. Fish Dis. 4:273-313.

Taylor, R.S.L., Edel, F., Manabdhar, N.P., and Towers, G. H.N. (1996): Antimicrobial activities of southern Nepalese medicinal plants, J. Ethnopharmacol., 50:97-102.

Tepe, B.; Daferera, D.; Sokmen, A.; Sokmen, M. and Polissiou, M. (2005): Antimicrobial and antioxidant activities of the essential oil and various extracts of Salvia tomentosa Miller (Lamiaceae). Food Chem., 90:333-340. Ubillas, R. ; Jolad, S.D. ; Bruening, R.C., et al., (1994): SP303, an anti-viral oligomeric proanthocyanidin from the latex of Croton lechleri. Phytomedicine; 1:77-106. 